\title{
Wie is de Ander? De representatie van Japan in het Nederlandse televisieprogramma Wie is de Mol? (2010)
}

Dit artikel behandelt de beeldvorming van Japan, haar cultuur en bevolking in het populaire Nederlandse televisieprogramma 'Wie is de Mol?' uit 2010. Voortbouwend op theorieën over Oriëntalisme wijst een discoursanalyse op een evenwichtige en genuanceerde representatie van Japan. Herkenbaarheid voor de kijker komt echter terug in het gebruik van culturele stereotypen en oriëntalistische benaderingen, zij het vaak op creatieve wijze.

\section{Introductie}

Op II maart 20II werd Japan getroffen door een zware aardbeving. De daaropvolgende tsunami eiste vele mensenlevens en richtte grote schade aan, onder meer aan de kerncentrale in Fukushima aan de Japanse oostkust. Het was snel duidelijk dat de ramp van een zelfde grootteorde was als de Zuid-Oost-Aziatische tsunami (2004) en de aardbeving in Haït (2010), zowel in termen van omvang als mediaaandacht. Wekenlang stond Japan ongewild in de aandacht van de internationale media. Ook in België en Nederland was de belangstelling voor de ramp en de nasleep groot. Zo verscheen twee weken na de tsunami een markant artikel in De Volkskrant met als titel 'Japanners huilen ook' waarin journaliste Malou van Hintum japanoloog Henny van der Veer (Universiteit Leiden) interviewde. Van Hintum merkte op dat 'de Japanners als volk [...] wel erg gelaten - stoïcijns misschien zelfs' overkwamen en vroeg zich af of dit typisch Japans gedrag was. Van der Veer repliceerde enigszins geïrriteerd dat dergelijke reflecties en beschouwingen vooral iets zeggen over het Westerse stereotiepe denken dan dat het een accurate beschrijving geeft van de Japanse reactie op de ramp. Toen de verslaggeefster vervolgens opperde

* Martijn Huisman is in 2orr afgestudeerd als master 'Media, Culture \& Society' aan de Erasmus Universiteit Rotterdam. Correspondentie: Beltmolen 32, 2992DA Barendrecht (Nederland), E-mail: mhuisman86@hotmail.com

Stijn Joye (PhD) is docent aan de vakgroep Communicatiewetenschappen van de Universiteit Gent. Correspondentie: Korte Meer 7-II, 9000 Gent (België), E-mail: Stijn.Joye@UGent.be

Pieter Maeseele $(\mathrm{PhD})$ is als ZAP-BOF verbonden aan de faculteit Politieke en Sociale Wetenschappen van de Universiteit Antwerpen. Correspondentie: Sint-Jacobstraat 2, 2000 Antwerpen (België), E-mail: Pieter.Maeseele@ua.ac.be. 
dat de Japanners toch zeker verschillend moesten zijn van ons vanwege hun religieus-culturele achtergrond, antwoordde van der Veer:

'Veel Westerlingen denken dat wij hier de technologische kennis hebben, en dat de reflectie uit het Oosten komt. Onzin. Veel mensen zijn teleurgesteld als ze Japan bezoeken. Het is niet die oase van mystieke wijsheid die ze zich hadden voorgesteld. Japan is een moderne Westerse maatschappij, de derde economie van de wereld. Een land met een strikte scheiding van kerk en staat.' (Van Hintum, 20II, p. 6)

Dit opmerkelijke interview naar aanleiding van de tsunami is kenschetsend voor de problematiek die centraal staat in dit artikel: het bestaan en de representatie van diepgewortelde opvattingen en culturele stereotypen in Westerse cultuurproducten over niet-westerse culturen, in dit geval de economische wereldmacht Japan. Het interview was tevens aanleiding om de beeldvorming van Japan in niet-factuele mediaproducten te bestuderen gezien de wetenschappelijke relevantie van dergelijk onderzoek. Deze thematiek kent immers een lange onderzoekstraditie wat nieuwsberichtgeving betreft, maar beeldvorming van de culturele en etnische Ander in amusementsprogramma's en reality-televisieshows is nog grotendeels onderbelicht in communicatiewetenschappelijke literatuur, specifiek in Nederland en België. De centrale onderzoeksvraag van dit artikel luidt dan ook: hoe werd Japan, het land en zijn cultuur, gerepresenteerd in het populaire Nederlandse televisieprogramma Wie is de Mol? (WIDM) dat zich in zijn tiende seizoen (20I0) in Japan afspeelde? En in welke mate bevat dit beeld stereotypen die kenmerkend zijn voor, of een uiting van, een oriëntalistisch discours?

WIDM wordt geproduceerd en uitgezonden op de publieke omroep door de AVRO. Het concept draait rond tien bekende Nederlanders die wekelijks een aantal opdrachten dienen te vervullen waarbij één lid van de groep de rol van 'mol' vervult en moedwillig opdrachten saboteert. Wie op het einde de mol weet te ontmaskeren is de winnaar van het programma. Elk seizoen speelt zich af op een verre locatie zoals Mexico, Thailand, Australië of Japan. Het tiende seizoen dat plaatsvond in Japan bestaat uit tien afleveringen, goed voor 8,5 uur televisie. De keuze voor WIDM als studieobject is ten eerste ingegeven door het succes van het programma. Van oorsprong een Belgisch format, kluistert de show al meer dan een decennium lang vele Nederlanders aan de buis. In 20II trok het elfde seizoen gemiddeld twee miljoen kijkers, goed voor een marktaandeel van bijna 25,9\% terwijl het seizoen dat zich in Japan afspeelde gemiddeld I,7 miljoen kijkers trok per aflevering (marktaandeel van 23,7\%). Daarnaast heeft het programma in 200I een 'Gouden Beeld' voor het beste amusementsprogramma gewonnen en is het maar liefst vijf keer genomineerd geweest voor de 'Gouden Televizier-Ring', de belangrijkste en meest prestigieuze Nederlandse prijs voor een televisieprogramma. Voorgaande maakt het des te verrassender dat het programma, behoudens enkele bachelor- en masterscripties, 
tot op heden onder de radar van academici is gebleven. Ten tweede sluit de keuze voor een amusementsprogramma als WIDM aan bij de ideeën van Silverstone (2007) dat veel mensen enerzijds de wereld waarin ze leven zo goed als uitsluitend via media ervaren en anderzijds de neiging hebben om deze gemediatiseerde voorstelling van de wereld kritiekloos aan te nemen. De meerderheid van de bevolking komt met andere woorden hoofdzakelijk via dit soort populaire mediaproducten in contact met de 'Ander' of niet-westerse culturen en stelt er zich weinig tot geen vragen bij. Precies de grote groep kijkers die het programma wekelijks weet te bereiken en de indrukken of beelden dat het dit publiek geeft van andere landen en culturen, maakt WIDM van grote waarde als focus voor een onderzoek naar de beeldvorming van de Ander en het opsporen van stereotypen die mogelijk een uiting zijn van een oriëntalistisch discours in populaire Westerse amusementsmedia.

In het theoretisch luik van dit artikel gaan we dieper in op de academische discipline van het Oriëntalisme dat als conceptueel kader fungeerde voor het empirisch onderzoek. We besteden tevens aandacht aan academisch onderzoek naar de beeldvorming van onze case, Japan, in diverse populaire media. Na een bespreking van de gehanteerde methodologie, namelijk discoursanalyse, volgt een discussie van de belangrijkste bevindingen.

\section{Oriëntalisme als academische discipline en als discours}

Beeldvorming in de media van de brede relatie tussen het Westen en het Oosten wordt door academici al jaren bekeken en geanalyseerd vanuit het theoretisch raamwerk van Oriëntalisme. Aangereikt door Edward Said in zijn monumentale boek 'Orientalism. Western conceptions of the Orient' uit I978, was de theorie in eerste instantie gericht op Europese literatuur over het Midden-Oosten. Gelijklopend met de toepassing van de theorie door derden op andere regio's, culturen en periodes, zijn Saids theorieën en inzichten door de jaren heen onder andere uitgegroeid tot een belangrijk analytisch instrument en een volwaardige academische onderzoektak om representaties van de niet-westerse 'Ander' in de media te observeren (Bernstein, I997; Lockman, 20I0). Het zou echter afbreuk doen aan de rijkdom en diepte van Saids werk om Oriëntalisme uitsluitend te beperken tot dit ene aspect, daar het een bredere uiting is van Westerse culturele, politieke en ideologische discoursen over 'de Orient' bestaande uit 'supporting institutions, vocabulary, scholarship, imagery, doctrines, even colonial bureaucracies and colonial styles' (2003, p. I-2).

Oriëntalisme kan met andere woorden het best omschreven worden als een discours, een taalgebruik in alledaagse situaties als het gaat om het (re)presenteren van de Oriënt of het Oosten en de niet-westerse Ander. Volgens Hall (I997) definieert een discours echter niet alleen de manier hoe we over bepaalde zaken spreken, denken of deze representeren, maar legt het tevens beperkingen en restricties op. Betekenis 
wordt op deze manier gecreëerd binnen een bepaald 'interpretative framework'. Vanuit deze visie wordt Oriëntalisme naar voor geschoven als een dominant discours dat de Oriënt creëert, representeert en dus betekenis geeft, waarbij de klemtoon ligt op de veronderstelde verschillen ten opzichte van de Westerse wereld. In de woorden van Said (2003, p. 2) positioneert dit meer ideologische perspectief Oriëntalisme als een 'style of thought based upon an ontological and epistemological distinction made between 'the Orient' and (most of the time) 'the Occident'.' Dit expliciet gearticuleerde onderscheid met de inherente assumptie dat het ene inferieur is aan het andere, staat centraal in alle oriëntalistisch geïnspireerde teksten, theorieën en representaties. Het leidt bovendien tot een zowel actief als passief proces van 'Othering' waarbij de tegengestelde en inferieure 'Ander' gedefinieerd en gerepresenteerd wordt als de geografische, politieke en culturele entiteit die we zelf niet (willen) zijn en die we bijgevolg negatieve karaktereigenschappen kunnen toedichten (Gray, 2009). In de visie van Stuart Hall (I997) vallen deze elementen samen binnen een 'representational paradigm' waarbij er een sterk verband is tussen deze binaire tegenstellingen ('tropes of representation') en het proces van representatie en/of stereotypering. Dit verband omvat eveneens 'the power to represent someone or something in a certain way - within a certain "regime of representation"' (Hall, I997, p. 259) met daaraan gekoppeld het proces van betekenisgeving of -constructie. Teruggrijpend naar de notie van discours is Oriëntalisme, volgens Said, bovenal een Westers kennis- en betekenissysteem waarmee kennis over en representaties van de Oriënt naar het Westerse bewustzijn worden 'gefilterd' en zodoende geconstrueerd en gecontroleerd kunnen worden. Toegepast op mediarepresentaties en de case van Japan kunnen we bijvoorbeeld verwijzen naar een aantal recente Hollywoodfilms die zich in Japan afspelen zoals The Last Samurai (2003), Lost in Translation (2004) en The Fast and the Furious: Tokyo Drift (2006). Op individuele variaties na, figureren Japan en haar inwoners in deze films als achtergrond en enigszins passieve subjecten die in grote mate ondergeschikt staan aan en/of tot leven worden gewekt door de Westerse protagonisten die een leidende rol opnemen dan wel alles van op een zekere afstand aanschouwen.

Hoewel Oriëntalisme breed en veelvuldig is toegepast binnen mediastudies, besteedde Said zelf weinig (empirische) aandacht aan hedendaagse literatuur en andere massamedia als televisie en film maar focuste hij zich hoofdzakelijk op zeventiende, achttiende en negentiende eeuwse 'highbrow' Europese literatuur. Het is slechts in de marge hiervan dat Said laat optekenen dat in de postmoderne elektronische maatschappij de stereotypen waarmee de Oriënt wordt bekeken en beschreven niet verdwenen, maar integendeel versterkt aanwezig zijn in het aanbod van de massamedia. Hij merkt op dat mediaconsumenten in toenemende mate hapklare informatie voorgeschoteld krijgen en volgzaam moeten kiezen tussen mediaproducten die steeds meer een zelfde vast stramien volgen, wat maakt dat het discours en de praktijk van Oriëntalisme onverminderd onderdeel uitmaken van het hedendaagse media-aanbod (Said, 2003; Gray, 2009). Verder gaat Said echter niet 
in zijn analyse van populaire cultuur en massamedia, hetgeen een open doekje was voor criticasters zoals Irwin (2009) die Said verweet te focussen op een beperkte niche van literatuur en bijgevolg de realiteit te negeren dat het grote publiek hoofdzakelijk films en televisieprogramma's consumeert. Door Saids theorie toe te passen op een populaire televisieshow wensen we tegemoet te komen aan deze kritiek. Middels een discoursanalyse van WIDM willen we op deze manier het door Said gedefinieerde Oriëntalisme 'uitbreiden' enerzijds naar geografische normen door te focussen op Japan en anderzijds wat betreft mediavormen door de analyse van een populair en hedendaags mediaproduct.

De uitbreiding naar Japan hangt samen met Saids geografisch uitgangspunt bij het definiëren van de Oriënt, namelijk het aan Europa aangrenzende Midden-Oosten. Dat wordt gezien als de bakermat van de Europese beschaving en tevens thuis van de rijkste en oudste voormalige kolonies van Europa. Tegelijkertijd zag Said het Midden-Oosten als de culturele uitdager van Europa en de facto als een onveranderlijke 'Ander'. Het volstaat om de recente nieuwsberichtgeving in Europa over de Arabische Lente er op na te slaan om deze tendensen en de hedendaagse relevantie ervan te illustreren. Niettegenstaande de focus op het Midden-Oosten in het werk van Said en het feit dat Japan nooit een kolonie van Europa is geweest of in die mate heeft bijgedragen aan haar beschavingen en talen, hebben verschillende Japanse (o.a. Iwabuchi, I994; Inokuchi \& Nozaki, 2005; Nishihara; 2005) maar ook Westerse (o.a. Steadman, I970; Minear, I980; Rosen, 2000; Lie, 200I) academici met veel succes van Oriëntalisme gebruik gemaakt om de relaties tussen Japan en het Westen te analyseren en te verklaren. Minear (I980, p. 515) concludeert bovendien dat 'even in the absence of overt Western domination, the attitudes manifested in the discourse on Japan seem to resemble closely those of Said's Orientalism.' Veel van de mediastudies binnen dit onderzoekkader zijn echter uitgevoerd naar representaties van Japan en/of Zuidoost Azië in Amerikaanse media en cultuurproducten. In het volgende deel gaan we summier in op enkele relevante studies met betrekking tot de mediarepresentaties van Japan in het Westen, maar het is in deze belangrijk om te wijzen op het feit dat, naar onze kennis, een onderzoek naar de beeldvorming van Japan in Nederlandse en Belgische media vanuit een oriëntalistisch perspectief tot op heden onbestaande is.

\section{Beeldvorming van Japan in de media}

Voorgaande vaststelling sluit echter niet uit dat dit artikel zich inschrijft in een bredere traditie van onderzoek naar de representatie of beeldvorming van andere landen of niet-westerse culturen in Belgische en Nederlandse media. Zonder hier dieper op in te gaan verwijzen we, niet exhaustief, naar onderzoek door bijvoorbeeld Shadid (2005) naar de beeldvorming van moslims en de islam, d'Haenens en Bink (2006) naar de representatie van islam in de Nederlandse kranten, Van den Bulck 
en Broos (2009) naar de beeldvorming van etnische minderheden in Vlaamse media, en Westerik, Douma en Konig (2007) naar stereotypering van Duitsers op televisie. Zoals eerder aangegeven bleef Japan tot op heden een blinde vlek op de kaart.

Op internationaal vlak vinden we wel diverse communicatiewetenschappelijke studies terug, vaak vanuit een Cultural Studies perspectief, die ingaan op de mediarepresentatie van Japan en de culturele stereotypen die hier mee gepaard gaan. In grote lijnen wordt Japan doorgaans neergezet als mysterieus of ondoorgrondelijk, exotisch, bizar en soms gevaarlijk (Levick, 2005; Harada, 2006). De Japanse samenleving wordt traditioneel afgebeeld als een anonieme, cultureel homogene en monolithische gemeenschap met weinig individuele autonomie en ruimte voor emoties (Lie, 200I; Matsumoto, 2002). Een belangrijke kiem van dit Westers en oriëntalistisch- interpretatieve raamwerk ligt in de literaire werken van Westerlingen die vanaf het midden van de negentiende eeuw in Japan verbleven nadat het land zich in I854, na 250 jaar van isolatie, onder zware Amerikaanse druk had 'opengesteld' voor de rest van de wereld. Observaties door buitenlanders hebben lange tijd het beeld van Japan in het Westen bepaald. Iwabuchi (I994) stelt dat Japan nog steeds gezien wordt als een ietwat geïsoleerde en unieke culture entiteit, ondanks de vele politieke, economische en culturele veranderingen die het land ondergaan heeft. Het oriëntalistische discours over Japan drijft verder op een aantal archetypes zoals de traditionele krijgersfiguur van de samoerai of de meer moderne variant van de hardwerkende, loyale en soms sluwe zakenman ('samurai in suits') (Levick, 2005, p. I). Tot slot wijzen een aantal auteurs als Mitsuhiro (I989), Ueno (2002) en Inokuchi en Nozaki (2005) op het bestaan van een 'techno-Orientalism', hetgeen staat voor een populaire representatie van Japan die gebaseerd is op een dualiteit tussen het heden en het verleden, oftewel een combinatie van 'futuristic high-tech images of contemporary Japan and anachronistic images of feudal Japan' (Mitsuhiro, I989, p. I8).

In populaire mediaproducten worden deze kenmerken en gepercipieerde verschillen uitvergroot of dienen ze zelfs als basis voor het format. Dit laatste was het geval voor het reality-reisprogramma Lost in Tokyo dat zowel in Nederland (RTL5) als in België (2BE) werd uitgezonden, echter met weinig succes. ${ }^{\mathrm{I}}$ Deelnemers aan het programma werden in de 'jungle' van de Japanse hoofdstad aan hun lot overgelaten waarna in de opdrachten, het taalgebruik en de beeldvoering alle mogelijke (extreme) clichés over het land de revue passeerden: de Japanse 'yakuza' (maffia), de obsessie voor technologie, het karaokegebeuren, de maffe kapsels, manga (Japanse comics), de exotische geisha's, ... Het programma dreef primair op de ervaring van een cultuurshock en kende weinig bijval bij critici, mediaprofessionals en het grote publiek, in tegenstelling tot WIDM. Dit leidt ons tot de kernvraag van dit artikel: in welke mate vinden we dezelfde culturele stereotypen en elementen van een oriënta- 
listisch discours terug in het Japan-seizoen van WIDM? Deze vraag zullen we beantwoorden aan de hand van een discoursanalyse.

\section{Methodologie}

Centraal in dit onderzoek naar de beeldvorming van Japan in WIDM staan enerzijds de idee dat '[media] narratives are means of understanding the social world' (Pantti, 2009, p. 89-90) en anderzijds het concept van discours. In navolging van Jørgensen en Phillips (2002, p. I) beschouwen we discours als 'a particular way of talking about and understanding the world.' Met andere woorden, discours is een (sociaal gedeelde) verzameling van ideeën, beelden en praktijken (Machin \& Jaworski, 2006 , p. 35I) die tot uiting komen in het taalgebruik of in een mediaproduct. Een discours, zoals Oriëntalisme, is dus een representatie van de wereld die zowel een specifieke realiteit reflecteert als actief construeert door betekenissen toe te kennen (Phillips, 2006). De premisse daarbij is dat taal niet neutraal is en niet losstaat van de werkelijkheid maar deze in tegendeel construeert en verklaart. Naar methodologie toe vertaalt dit zich concreet in de vereiste dat een empirische analyse van discours niet gereduceerd mag worden tot enkel het taalgebruik of de multimodale tekst maar dat discours binnen zijn sociale context geanalyseerd moet worden (Jørgensen \& Phillips, 2002) waarbij verwezen kan worden naar de productiecontext en bredere sociale praktijken zoals politiek, economie en ideologie. Volgens van Dijk (I988, p. I5) vormt voornamelijk ideologie de basis van een discours in de zin van de gedeelde sociale representaties. Ideologie verwijst daarbij naar 'some organised belief system or set of values that is disseminated or reinforced by communication' (McQuail, 2000, p. 497). Ideologische strategieën worden vaak gearticuleerd in de zin van een polarisatie tussen wij (op een positieve wijze gerepresenteerd) en $z i j$ (de 'out-group' of de 'Ander' die negatief voorgesteld of gestereotypeerd wordt) (van Dijk, 2009). Dit sluit aan bij de ideeën en representaties over het Oosten zoals deze circuleren in het Westen en onderdeel uitmaken van een oriëntalistisch discours. Een discoursanalyse van mediateksten biedt kortom inzicht in hoe groepen, individuen en hun (veronderstelde) identiteiten worden gerepresenteerd (Smith \& Bell, 2007), zoals Japan in WIDM. Het is hierbij van belang om expliciet aan te geven dat het in dit artikel gepresenteerde onderzoek niet de doelstelling heeft om de correctheid of accuraatheid van deze representaties na te gaan, noch om bij voorbaat het programma als oriëntalistisch te bestempelen. Integendeel, de studie werd opgezet en aangevat als een diepgaande exploratie van de werking en functie van hedendaagse representaties van een niet-westerse cultuur in een populair Westers entertainment-programma.

Het onderzoeksdesign is bijgevolg opgebouwd uit twee fases waarbij in een eerste kwalitatief vooronderzoek een diepte-interview met de makers van het programma plaatsvond. Het semi-gestructureerde interview met Anton Jongstra (eindredacteur) 
en Aldo Paape (productiemanager) werd afgenomen door één van de auteurs op I april $201 \mathrm{I}$ in Amsterdam en duurde ongeveer twee uur. Vervolgens werd het interview getranscribeerd, gecodeerd en geanalyseerd volgens de methode van kwalitatieve inhoudsanalyse (Wester \& Peters, 2004, pp. 83-I03). De topiclijst voor dit interview ging onder meer in op het concrete productieproces, de montage en de doelstellingen van de show alsook op de individuele motivaties en professionele praktijken van de programmamakers. De bevindingen van het vooronderzoek werden meegenomen in de tweede fase van onderzoek, namelijk de discoursanalyse van het programma. De onderzoeksmethode van discoursanalyse is de afgelopen jaren steeds populairder geworden in allerlei academische gebieden. Binnen het communicatiewetenschappelijk domein wordt de methode voornamelijk aangewend om te achterhalen op welke manieren een mediatekst zoals een televisieprogramma betekenis creëert en overbrengt (Casey et al., 2007). Met andere woorden, discoursanalyse tracht de betekenis achter de sociale constructie van woorden, geluid en beelden te achterhalen (Smith \& Bell, 2007, p. 80). Dit impliceert een kwalitatieve benadering waarbij er geen vaste regels zijn betreffende de validiteit en betrouwbaarheid van het onderzoek maar wel enkele vuistregels. Smith en Bell (2007) wijzen er bijvoorbeeld op dat het belangrijk is om de analyse van de mediatekst te laten steunen op vaststellingen uit de theorie en bevindingen van andere studies, dit om subjectieve interpretatie door de onderzoeker zo veel als mogelijk te vermijden. Concreet stellen Jørgensen en Phillips (2002, p. I73) verder dat

' $\mathrm{t}]$ he analysis should be solid. It is best if interpretation is based on a range of different textual features rather than just one feature. The analysis should be comprehensive and $[\ldots]$ presented in a transparent way'.

Het empirisch onderzoek waarop dit artikel is gebaseerd werd bijgevolg systematisch uitgevoerd en maakte, naast de hier gepresenteerde discoursanalyse, gebruik van een uitgebreide literatuurstudie met uitgewerkt theoretisch kader en, zoals eerder aangegeven, van het diepte-interview met de programmamakers om bevindingen en inzichten te funderen en te kaderen. Wegens de beperkte ruimte zullen we ons in de resultatensectie echter voornamelijk richten op de bevindingen van de discoursanalyse.

Tot slot, een kort woord over de concrete werkwijze. Specifiek wat het opsporen van een mogelijk oriëntalistisch discours in mediateksten zoals WIDM betreft, biedt het werk van Said (2003, p. 2I) enige methodologische houvast: 'the things to look at are style, figures of speech, setting, narrative devices, historical and social circumstances, not the correctness of the representation nor its fidelity to some great original.' Levick (2005) voegt daar aan toe, vanuit zijn analyse van de nieuwsberichtgeving over Japan in Amerikaanse kranten, dat ten eerste moet worden nagegaan of Japan als exotisch wordt gerepresenteerd door het gebruik van woorden als 'mysterieus', 'uniek' en 'vreemd'. Vervolgens is het van belang om te onderzoeken of Japan 
en haar bevolking worden gearticuleerd als monolithisch en/of onveranderlijk waarbij beweringen als 'de Japanners zijn...' en 'typisch Japans' kritisch dienen te worden behandeld. Ten derde worden articulaties van de samoerai of andere krijgers uit de Japanse geschiedenis te pas en te onpas gebruikt bij representaties van het moderne Japan. Bovenstaande methodologische opmerkingen van zowel Said als Levick waren de leidraad in het analyseren van de representatie van Japan in WIDM. Conform het cyclische karakter van kwalitatief onderzoek (Wester \& Peters, 2004) werd het beeldmateriaal tweemaal bekeken. De transcripties gemaakt tijdens deze sessies dienden als de fundering voor de uiteindelijke discoursanalyse. Naast het visuele aspect werd bijzondere aandacht besteed aan het auditieve, namelijk alle dialogen, de voice-over, en de geluiden, zowel diëgetische (deel uitmakende van de originele opname) als non-diëgetische (niet in de oorspronkelijke opname zoals de soundtrack). Centraal in de discoursanalyse staan de interacties met de Japanse bevolking door de kandidaten, en de opmerkingen, beweringen over en representaties van Japan en haar cultuur.

\section{Resultaten en discussie}

Alvorens in te gaan op de resultaten van de discoursanalyse bespreken we kort de belangrijkste bevindingen van het kwalitatief vooronderzoek. Het interview met de programmamakers gaf ten eerste duidelijk aan dat deze een bepalende rol spelen in de beeldvorming. Uit het gesprek bleek namelijk een hoge mate van persoonlijke affiniteit met en interesse in het land, die zich onder meer uitten in een zeer professionele houding tijdens het filmen en monteren. Zich bewust zijnde van de clichés en stereotypen over Japan, was het volgens Jongstra en Paape essentieel dat het productieteam deze (grotendeels) trachtte te vermijden en zich niet focuste op extremen. Echter, beide makers gaven meteen ook duidelijk aan dat zij zich, ondanks het grote publiek dat bereikt wordt met het programma en de link met een publieke omroep hetgeen bepaalde verwachtingen schept naar beeldvorming toe, niet verantwoordelijk voelden voor het wel of niet gebruiken van stereotypen. Het uitgangspunt en/of de uitdaging voor de makers daarbij was dat de overgrote meerderheid van de kijkers geen persoonlijke (reis)ervaring heeft met Japan of Japanners. De kennis en het beeld dat men heeft van Japan is met andere woorden indirect, want hoofdzakelijk gevormd door de media. Concreet grepen de makers van het programma dus frequent terug naar beproefde technieken en beelden om een bepaalde 'Japanse' sfeer te kunnen creëren die herkenbaar is voor de kijkers thuis. Paape vatte deze instelling als volgt samen: 'Het is, denk ik, een mix. Een beetje bevestigend, maar toch ook wel strevend naar het voorkomen van de standaard stereotypen.' Met andere woorden, de programmamakers maakten vanwege de vereiste van herkenbaarheid weliswaar gebruik van culturele stereotypen, maar streefden er tegelijkertijd naar om dit met mate en op een genuanceerde en creatieve wijze te doen waarbij Japan niet als vreemd en bizar werd gerepresenteerd. In de discours- 
analyse komen we uitgebreid terug op deze dimensie van herkenbaarheid in relatie tot het gebruik van stereotypen.

Een tweede vaststelling betrof de visie van de programmamakers op de kijker. Uit het interview bleek dat de makers wel een bepaalde voorkennis van de kijkers verwachten. In de tweede aflevering van het seizoen komen bijvoorbeeld 'yakuza', de Japanse maffia, voor. Zij worden door het productieteam echter opzettelijk niet zo genoemd om de Japanse medewerkers aan het programma niet ontevreden te stellen. Bovendien zouden Nederlandse kijkers toch wel begrijpen dat de mannen in zwarte pakken en zonnebrillen verwijzen naar de Japanse maffia, aldus Anton Jongstra. Met andere woorden, een zekere voorkennis of beeld van het land wordt tot op bepaalde hoogte verondersteld. Dit beeld, zo stelden we eerder vast, wordt op zijn beurt grotendeels ingevuld door representaties in populaire mediaproducties (Silverstone, 2007).

Tot slot werd in het gesprek dieper ingegaan op de motieven van de makers om Japan uit te kiezen voor het tiende seizoen van WIDM. Eindredacteur Jongstra verklaarde dat Japan sinds lang een persoonlijke favoriet was om naar toe te reizen en wel omwille van een grote nieuwsgierigheid naar het land: 'Ik was zo nieuwsgierig naar Japan en verwachtte er zoveel van. Dat het anders was. Ja, een andere wereld die perfect was voor De Mol.' In zijn formulering van de verwachtingen merken we een sterke notie van 'Othering' van Japan en bijgevolg van het bestaan van enkele - onuitgesproken - vooroordelen of stereotypen over het land als radicaal verschillend met of anders als Nederland. Dit element nemen we eveneens mee in de bespreking van de discoursanalyse.

Uit het interview met de programmamakers en de discoursanalyse kwamen enkele grote thematische categorieën naar boven waarrond we het resterende deel van deze resultatensectie zullen organiseren: het format van het programma, de factor van herkenbaarheid, de rol van de kijker, en de dualiteit tussen traditioneel en modern. Zoals eerder aangegeven is de onderliggende doelstelling van de discoursanalyse het opsporen van stereotypen als uiting van oriëntalistische praktijken in de beeldvorming van Japan.

\section{Het format van het programma}

WIDM volgt qua opbouw de structuur van een typisch televisieformat waarbij de premisse elk jaar hetzelfde is ongeacht de locatie. Dit impliceert dat het programma in eerste instantie om het spelelement draait waarbij het land waarin WIDM zich afspeelt kan worden gezien als een soort van 'interactieve achtergrond'. Hiermee willen we echter niet insinueren dat het programma niets van het land en haar bevolking laat zien. Integendeel, elke aflevering bevat opdrachten die geïnspireerd zijn door of gerelateerd aan Japan. Verder zijn er verschillende intervallen of momenten tussen de opdrachten in waarin beelden van het dagelijkse leven en de 
omgeving worden gemonteerd om de kijker wat mee te geven over het land en de 'vreemde' cultuur waarin het programma zich afspeelt. Het onderzochte seizoen van WIDM bevat bijvoorbeeld regelmatig intervallen met beelden van Japanners, jong en oud, die in kimono op straat wandelen. Hoewel de kimono zeker niet een alledaagse kledingstijl is in Japan wordt het wel in elke aflevering getoond, maar daarover later meer. Een ander voorbeeld heeft betrekking tot het invullen van de opdrachten. Zo verweven de programmamakers op innovatieve wijze het van origine Japanse karaoke in een opdracht die zich afspeelt in een stijlvolle theaterzaal. Het Japanse stereotype van karaoke wordt daarbij gebruikt ter inspiratie, maar in tegenstelling tot andere Westerse televisieprogramma's en films representeren de programmamakers het niet op een beledigende wijze door te suggereren dat karaoke een marginaal tijdverdrijf is of alleen leuk is wanneer men voldoende gedronken heeft. Kortom, Japan vormt binnen het format van WIDM niet alleen een mooie of exotische achtergrond voor het spel maar wordt in verschillende afleveringen ook actief 'gebruikt' ter inspiratie van opdrachten of om het beoogde gevoel van herkenbaarheid bij de kijkers los te weken. Dit laatste zullen we verder in detail bespreken.

\section{Herkenbaarheid met betrekking tot de beeldvorming}

Uit de discoursanalyse bleek dat vooral tijdens de voornoemde intervallen maar ook tijdens opdrachten, interviews en introducties de makers uitdrukkelijk aan een 'Japanse sfeer' appelleren. Specifieke beelden worden daartoe in de eindmontage gezet en bepaalde muziek wordt gebruikt om de kijker expliciet te laten zien en horen dat het programma in Japan plaatsvindt (cf. infra). Dit impliceert dat Japan gearticuleerd wordt op manieren die herkenbaar zijn voor de Nederlandse kijkers. Om deze herkenbaarheid te waarborgen gebruiken de makers fragmenten, afbeeldingen, geluiden en verhaallijnen die tot op bepaalde hoogte al bekend zijn bij de Nederlandse kijker. Deze elementen worden veelvuldig aangehaald tijdens het verloop van het seizoen, hetgeen hun centrale rol in de beeldvorming onderlijnt.

Een merkwaardig voorbeeld dat in vrijwel alle afleveringen aan bod komt is sushi. Sushi wordt prominent weergegeven en vaak in close up getoond alsof de programmamakers de kijkers duidelijk willen maken dat Japanners enkel en alleen maar sushi eten. Sushi wordt zodoende gearticuleerd als een kernonderdeel van de Japanse (culinaire) identiteit en levenswijze. Hoewel dat tot op bepaalde hoogte ook zo is, eten de kandidaten in WIDM waarschijnlijk (veel) meer sushi dan de doorsnee Japanner ('ik kan geen sushi meer zien', aldus één van de deelnemers) en lijkt de montage haast op een culinair 'essentialisme'. Andere voorbeelden van representaties en montagetechnieken die geënt zijn op mainstream culturele stereotypen over Japan zijn de kimono (cf. supra), de figuur van de samoerai, mystieke tempels als decor voor de opdrachten, Oosterse muziek op de soundtrack, ...(cf. infra). Het achterliggende idee om deze stereotypen te gebruiken is uiteraard nauw gerelateerd aan de reden waarom het programma in eerste instantie naar Japan afreisde: in het 
voorbereidende interview gaven de makers immers aan dat ze er verwachtten verschil te vinden, een 'hele andere wereld' in de woorden van eindredacteur Anton Jongstra. Op het belang en de rol van dit verschil komen we later nog terug.

\section{Rol van de kijker: agency en voorkennis}

Conform de bevindingen uit het voorbereidend gesprek met de programmamakers, kunnen we eveneens uit de discoursanalyse van WIDM uitmaken dat de makers een zekere mate van 'agency' of zelfstandigheid verlangen van hun kijkers. Het programma geeft maar heel zelden op een directe manier informatie over Japan, haar bevolking en cultuur. Bovendien wordt er geen gebruik gemaakt van een voice-over die enige toelichting geeft over het land waar het spel zich afspeelt. De kijker krijgt als het ware vrijheid of autonomie om zijn/haar eigen interpretatie te vormen van het land, al wordt hij/zij in dit proces uiteraard wel gestuurd door de makers in hun keuze van montage (visueel en auditief) van de intervallen en de opdrachten die vaak gerelateerd zijn aan de omgeving/het land. Alleen in aflevering acht worden enkele uitspraken gedaan over Japan door presentator Pieter-Jan Hagens. Hij vertelt rechtstreeks in de camera hoe de Japanners lange tijd bekend stonden omwille van hun kopieerkunsten, met als belangrijkste voorbeeld de Tokyo Tower. Waarna hij afsluit met de volgende woorden: 'deze nep Eifeltoren'. Dergelijke uitspraken wijzen op twee manieren naar sporen van een oriëntalistisch discours. Ten eerste is het een bevestiging van een hardnekkig stereotype binnen de Westerse maar vooral Amerikaanse beeldvorming van Japan dat binnen dit denken gerepresenteerd wordt als een land dat gedreven is in het kopiëren of imiteren (van bijvoorbeeld Westerse gebouwen of technologie) maar niet in het creëren, wat doorgaans voorbehouden blijft voor het Westen. Ten tweede verwijzen dergelijke uitspraken rechtstreeks naar een kernidee binnen het denken van Said, namelijk de vaststelling dat in vergelijkingen tussen het Westen en het Oosten (Oriënt) beide partijen nooit als gelijk of evenwaardig worden gezien. Het is integendeel een sterk hiërarchische relatie waarbij de 'Ander' vrijwel altijd als inferieur wordt beschouwd aan het Westen. Specifiek voor deze uitspraak betreft het hier een binaire tegenstelling tussen enerzijds authentiek of origineel (Franse Eifeltoren) en anderzijds imitatie of kopie (Tokyo Tower).

\section{Japan tussen traditioneel en modern}

Het element dat echter het meest in het oog sprong tijdens de discoursanalyse is de representatie van Japan in termen van een interne dualiteit of paradox. In alle afleveringen van WIDM wordt de volgende dualiteit voortdurend benadrukt. Enerzijds wordt Japan voorgesteld als een oud, mysterieus land vol met tempels, priesters en rituelen uit vroegere tijden. Met andere woorden, het zogenaamde 'zen-Boeddhistische' Japan dat zo vaak verheerlijkt wordt in Hollywoodfilms of andere Westerse cultuurproducten. Anderzijds vinden we in de beeldvorming van WIDM het moderne, hedendaagse Japan terug dat gelijk is aan het Westen qua welvaart, technologie en architectuur. Hoewel beide 'identiteiten' in beeld worden gebracht, neigt 
het programma echter het meest naar het traditionele Japan, het voor veel Westerse toeristen ook enige echte Japan. Laten we deze techno-oriëntalistische (cf. supra) dualiteit in de beeldvorming nader bekijken en illustreren aan de hand van een aantal fragmenten.

Een eerste fragment brengt ons bij het begin van de allereerste aflevering. Presentator Pieter-Jan Hagens introduceert het nieuwe seizoen aan de kijker tegen de nachtelijke skyline van de Japanse hoofdstad Tokio met de volgende woorden:

'Tien bekende Nederlanders strijden om de pot in 'Wie is de Mol?' Voor de tiende serie reizen ze af naar het land van shogun en samoerai. Ze reizen naar Japan.'

In de allereerste twintig seconden van het seizoen merken we direct een dualiteit op in de tekst door een scherpe tegenstelling in woord en beeld. Verbaal wordt Japan gearticuleerd als 'het land van de shogun en samoerai', aldus verwijzend naar de krijgsklasse van het oude, vroegmoderne Japan. Visueel wordt het beeld echter gedomineerd door de skyline van Tokio wat refereert aan het moderne, huidige Japan. Doorheen het seizoen is deze interne dualiteit steeds aanwezig, sluimerend dan wel expliciet. Uit de analyse bleek niettemin dat de programmamakers een prominentere rol toewijzen aan het beeld van het traditionele Japan.

Nog in de eerste aflevering wordt bijvoorbeeld de link gelegd met het spirituele element dat centraal staat in veel Westerse representaties van het traditionele Japan. De kandidaten ontmoeten de presentator voor het eerst in een tempel. Terwijl de deelnemers de lange trappen oplopen wordt er een 'Oosterse', mysterieuze, maar ook rustgevende en exotische sfeer opgeroepen door beelden van priesters in traditionele gewaden en door middel van de soundtrack. Eenmaal boven zwaaien de immense deuren van de tempel open en zegt presentator Hagens tegen de kandidaten, en dus ook aan de kijker thuis: 'Goedemorgen. Welkom in Japan'. Deze introductie zet onmiddellijk de toon voor de hele serie waarin Japan veel als een traditioneel land vol met mysterieuze tempels en rituelen zal worden gerepresenteerd. Samen met de eerder aangehaalde introductie van de presentator wordt de kijker zodoende reeds van bij het begin een dominant beeld gepresenteerd van het hedendaagse Japan als 'caught in history' en gekenmerkt door traditionele elementen als tempels en samoerai. Daarbij speelt de soundtrack van het programma, een volgens de makers vaak ondergewaardeerd element van het programma, een zeer belangrijke rol. Veel muziek in WIDM is afkomstig van de Chinese film House of the Flying Daggers (2004) en wordt strategisch toegepast om een Oosterse of Japanse sfeer te creëren of te versterken.

Ook in latere afleveringen voert het traditionele Japan de boventoon. In de derde aflevering bezoeken de kandidaten een traditioneel gebouw omgeven door een grote 
Japanse tuin. Op de soundtrack is opnieuw dezelfde Oosterse, mysterieuze muziek te horen. Binnen worden de bekende Nederlanders in het Japans begroet door een Japanse vrouw in kimono. De setting - het gebouw en de tuin - alsmede de muziek en de niet vertaalde begroeting in het Japans voeden een mysterieuze atmosfeer, die door één van de kandidaten zelfs wordt omschreven als 'onheilspellend'. Enkele afleveringen later zijn de deelnemers opnieuw op bezoek in een Boeddhistische tempel. Een zelfde scenario als in de eerste aflevering ontvouwt zich: de kandidaten beklimmen ook nu de steile trappen en worden bovenaan begroet door de presentator: 'Goedemorgen. Het Boeddhistische tempelcomplex van Yamadera is twaalfhonderd jaar oud.' Hierna volgt onmiddellijk een snelle montage van beelden van het complex met in Westerse ogen vreemde standbeelden en de bossen rond de tempels. Deze mise-en-scène en de combinatie van montagetechnieken, beelden en audio dragen bij tot het beeld van de locatie als een kalme, mysterieuze en exotische plaats, conform de stereotiepe presentaties van Japan als een 'Zen land'. De Boeddhistische tempel is in dit geval niet alleen een twaalfhonderd jaar oude tempel, maar representeert ook een andere realiteit: dit van de ogenschijnlijk onveranderbare, traditionele en mysterieuze Oriënt waar rust en spiritualiteit te vinden zijn, ideaal voor contemplatie en reflectie, hetgeen niet meer mogelijk is in het opgejaagde en materialistische Westen. Tot slot krijgen de kandidaten in een van de laatste afleveringen een opdracht waar zogenaamde 'ninja' in voorkomen, hetgeen eveneens een typische representatie of stereotype is waarmee Japan vaak wordt geassocieerd. Samen met de samoerai behoren de ninja immers tot het domein van de mythische Japanse krijgers en refereren ze aan vroegere tijden en een traditioneel Japan.

Tegenover dit dominante beeld staan de drie laatste afleveringen die zich nog in Japan afspelen. ${ }^{2}$ Qua beeldvorming verschuift de focus hier naar het moderne Japan. We krijgen beelden van zakenmannen in pak, jonge vrouwen met extravagante kapsels en kledij, karaokebars, moderne infrastructuur en architectuur... De geluidsband bestaat vooral uit drukke verkeersgeluiden en overwegend opzwepende, moderne muziek, hetgeen een gevoel van drukte en bedrijvigheid oproept. De opdrachten spelen zich nu hoofdzakelijk af in 'de betonnen jungle' die Tokio heet, een overduidelijk urbane omgeving met dik dertig miljoen inwoners. Een opmerkelijk fragment vinden we terug in aflevering zeven. In deze aflevering viel de keuze voor de setting van een opdracht op het beroemde station van Shinjuku, het drukste trein- en metrostation ter wereld. Nadat het spel is geëindigd in het station zoomt de camera uit en krijgt de kijker een goed overzicht van de omgeving: volgebouwd met wolkenkrabbers, overal neonlichten en andere reclame-uitingen, en schijnbaar dag en nacht bevolkt door duizenden Japanners. Het beeld gaat vervolgens op zwart en seconden later zien we opeens een vreedzaam, traditioneel Japans gebouw omgeven door een grote tuin, geheel ontdaan van de drukte van de stad. Zelfs in deze stedelijke en moderne setting blijft het programma dus teruggrijpen naar het meer traditionele, rustieke en mysterieuze beeld van Japan. Een beeld dat 
voor de Westerse kijker ver genoeg staat of verschilt van de eigen leefwereld, maar tegelijkertijd ook voldoende herkenbaarheid of vertrouwdheid oproept daar het vertrekt van heersende culturele stereotypen.

\section{Discussie}

Een dominant thema in de representatie van Japan is contradictie of dualiteit. De programmamakers van WIDM appelleren sterk aan het concept van techno-Oriëntalisme door continu te spelen met de tegenstelling tussen modern of hightech (de skyline, de stad, het technologische aspect) en het traditionele (de natuur, het platteland, de tempels), maar altijd met een nadrukkelijke voorkeur voor het traditionele dat wordt afgebeeld en verbeeld door tempels, kimono's, theehuizen en -ceremonies, shogun, samoerai, ninja en sushi. Deze articulaties van het traditionele komen vaak voor in de Westerse films en televisieseries in en over Japan. Ze volgen een typisch oriëntalistische vertelwijze waarin de Oriënt (Japan) staat voor mystiek en reflectie, wat tegenover het ongebreidelde materialisme van het Westen wordt gepositioneerd. We kunnen met andere woorden een dubbel proces van beeldvorming onderscheiden. Enerzijds abstraheert het traditionele Japan, gesymboliseerd door onder meer de tempels, het tegenwoordige Japan en anderzijds biedt deze oriëntalistische representatie een tegenhanger voor het Westen dat op zoek is naar spiritualiteit.

Uit de discoursanalyse bleek verder dat in WIDM hoofdzakelijk gebruik werd gemaakt van culturele stereotypen en oriëntalistische technieken met als bedoeling herkenbaarheid voor de kijker te creëren. Het belang van herkenbaarheid kwam reeds sterk naar boven in het diepte-interview met de makers en om dat te bereiken zijn de programmamakers enigszins gedwongen om aan te sluiten bij het courante 'representational paradigm' (bv. Hall, I997) of de heersende traditie binnen Westerse film en televisie om Japan af te beelden. Dit impliceert bijvoorbeeld het verwijzen naar de breed toegepaste en gekende culturele stereotypen zoals ninja, samoerai, yakuza, karaoke, sushi en Zen Boeddhisme. Niettemin is het van belang aandacht te schenken aan de positieve manier waarop de programmamakers omgaan met deze oriëntalistische verhaalwijzen, elementen en montages. Zoals eerder aangehaald, ligt de klemtoon van het programma op het spelgegeven en worden bovenstaande aspecten aangewend op enerzijds een veelal innovatieve en speelse wijze (zie ook de karaoke-opdracht) en anderzijds vanuit een ondersteunende rol. In tegenstelling tot bijvoorbeeld Lost in Translation en Lost in Tokyo, verliest WIDM zich niet in het actief 'Anders' maken van Japan en haar cultuur en bevolking. Bovendien worden de Japanners niet gerepresenteerd als vreemd, onbegrijpelijk of bizar, hetgeen een frequent toegepast uitgangspunt is van veel Westerse producties in en over Japan. Tot slot kunnen we ook wijzen op het feit dat het Nederlandse productieteam een actief beroep deed op lokale medewerkers met wiens mening rekening werd gehouden bij het uitwerken van de verschillende opdrachten (bv. het niet vermelden van de yakuza). Concluderend kunnen we vaststellen dat WIDM als Westers 
mediaproduct in zijn beeldvorming van een niet-westerse cultuur de notie van Shohat en Stam (1994) bevestigt, namelijk dat media actief kunnen deelnemen en bijdragen aan het proces van 'Othering' (zoals Lost in Translation en Lost in Tokyo) maar daarnaast ook crosscultureel begrip kunnen promoten in de specifieke manier waarop andere landen en mensen worden afgebeeld en gerepresenteerd.

\section{Conclusie}

Kennis over en een beeld van niet-westerse culturen kan men verkriigen en zich vormen door reizen en persoonlijke ervaringen met deze culturen, maar dat is slechts voor een minderheid van de bevolking het geval. Voor de anderen vervullen media deze rol (Silverstone, 2007), waarbij we verwijzen naar internationale nieuwsberichtgeving, reisprogramma's en amusementsmedia. Het uitgangspunt van dit artikel was de representatie van Japan, zijn cultuur en bevolking in het tiende seizoen van het populaire Nederlandse televisieprogramma Wie is de Mol? (WIDM). In welke mate bevat dit beeld culturele stereotypen over Japan die een uiting zijn van een oriëntalistisch discours?

In eerste instantie valt op te merken dat het programma in het algemeen een behoorlijk gebalanceerd en genuanceerd beeld van Japan schetst in vergelijking met soortgelijke televisieprogramma's en films over Japan. Een eerste mogelijke verklaring hiervoor kan gevonden worden in het specifieke format van het programma dat in de eerste plaats gericht is op de kandidaten en hun zoektocht naar de 'mol', waarbij het land en zijn bevolking vooral als een interactieve achtergrond of decor fungeren. Bijgevolg is veel informatie over het land van indirecte aard. De kijker put informatie over Japan uit de locaties, muziek en vooral de beelden in de intervallen tussen de opdrachten. Ook de opdrachten zelf zijn een bron van informatie voor de kijker, daar Japan niet alleen een exotische achtergrond voor het spel is maar in verschillende afleveringen ook actief 'gebruikt' wordt bij de concrete uitwerking en invulling van opdrachten. Ten tweede viel uit het interview met de programmamakers af te leiden dat deze gebalanceerde weergave in grote mate te danken is aan de persoonlijke affiniteit en professionele houding van het productieteam. De discoursanalyse wees echter uit dat WIDM zich eveneens insluit in een bepaalde traditie of 'representational paradigm' van het in beeld brengen van Japan dat kenmerkend is voor veel Westerse films en televisieprogramma's. Het sleutelwoord hierbij is herkenbaarheid. Voor de kijker moet het immers meteen duidelijk zijn dat het programma zich daadwerkelijk in Japan afspeelt. Om dat te bereiken maken de programmamakers gebruik van culturele stereotypen zoals de ninja, de samoerai, de yakuza, karaoke, sushi en Zen Boeddhisme, zij het vaak op innovatieve en speelse wijze. WIDM maakt bovendien niet de fout om te vervallen in extremen door uitsluitend te focussen op een beeld van Japan als vreemd, ondoorgrondelijk en bizar. De onderliggende drijfveer van het programma en de beeldvorming van Japan is in 
deze een contradictie. Vanzelfsprekend betreft het verschillen tussen Nederland en Japan maar ook binnen de representatie van Japan staan verschillen centraal: tussen traditioneel en modern, platteland en grote stad. De meerwaarde van het opnemen in een ander land berust uiteraard op deze dynamiek van 'Othering' en een discours van Oriëntalisme, of in het bijzonder van techno-Oriëntalisme. Deze vormen of uitingen van een oriëntalistisch discours zijn echter gerelateerd aan een streven naar herkenbaarheid en tegelijkertijd genuanceerd door een diep respect vanuit de programmamakers voor het land.

Dit artikel, en het onderzoek waar het op gebaseerd is, onderschrijven echter de bevindingen en kritieken van Edward Said, die tot zijn dood in 2003 volhield dat Oriëntalisme zeker geen verschijnsel uit het verleden was, maar nog altijd een dominante of frequent toegepaste stijl is binnen Westerse cultuurproducten om de non-westerse 'Ander' te omschrijven, begrijpen, representeren en uiteindelijk te controleren. Dit is een belangrijke conclusie die de deur opent naar verder toekomstig onderzoek naar dit onderwerp. Immers, in recente jaren is er sprake van een verschuiving in de internationale politieke en economische verhoudingen waarbij niet-westerse landen zoals India en Brazilië enorm in opkomst zijn en anderen zoals Japan en China zelfs al gevestigde nieuwe grootmachten zijn. Hoe zij worden afgebeeld en gerepresenteerd in de Westerse media zal van groot belang zijn voor hoe de bevolkingen van Westerse landen met deze verschuivingen en veranderingen zullen omgaan. De analyse van amusementsprogramma's met een groot publiek bereik zoals WIDM maar ook nieuwsuitzendingen op basis van het werk van Said kan daarbij relevante inzichten opleveren.

\section{Literatuurlijst}

Bernstein, M. (I997). Introduction. In M. Bernstein \& G. Studlar (Eds.), Visions of the East: Orientalism in film (pp. I-I8). Londen \& New York: I.B. Tauris Publishers.

Casey, B., Casey, N., Calvert, B., French, L. \& Lewis, J. (Eds.). (2007). Television studies. The key concepts. Londen: Routledge.

d'Haenens, L. \& Bink, S. (2006). Islam in de Nederlandse media: focus op het Algemeen dagblad. Tijdschrift voor Communicatiewetenschap, 34, nr. 4, 35I-367.

Gray, J. (2009). We're not in Portland anymore: Lost and its international others. In R. Pearson (Ed.), Reading Lost: Perspectives on a hit television show (pp. 22I-239). Londen \& New York: I.B. Tauris Publishers.

Hall, S. (I997). The work of representation. In S. Hall (Ed.), Representation: Cultural representations and signifying practices (pp. 13-74). Londen: Sage.

Harada, Y. (2006, June). The Occident in the Orient or the Orient in the Occident? Paper gepresenteerd op het $\mathrm{I}^{\mathrm{e}}$ Biennial Conference of the Asian Studies Association of Australia. Wollongong, Australië.

Inokuchi, H. \& Nozaki, Y. (2005). "Different than Us": Othering, Orientalism, and US middle school students' discourses on Japan. Asia Pacific Journal of Education, 25, nr. 1, 6I-74.

Irwin, R. (2009). Popular culture, Orientalism, and Edward Said. In Viewpoints. Orientalism's wake: The ongoing politics of a polemic (pp. 6-9).Washington, DC: The Middle East Institute. 
Iwabuchi, K. (I994). Complicit exoticism: Japan and its other. The Australian Journal of Media \& Culture, $8, n r .2,49-82$.

Jørgensen, M. \& Phillips, L. (2002). Discourse analysis as theory and method. Londen: Sage.

Levick, J. (2005). Japan in the U.S. press: Bias and stereotypes. Stanford Programme on International and Cross-cultural Education, http://spice.stanford.edu/docs/I2I

Lie, J. (200I). Ruth Benedict's legacy of shame: Orientalism and Occidentalism in the study of Japan. Asian Journal of Social Science, 29, $n r .2$ 249-26I.

Lockman, Z. (20IO). Contending visions of the Middle East. The history and politics of Orientalism (2nd ed.). Cambridge: Cambridge University Press.

Machin, D. \& Jaworski, A. (2006). Archive footage in news: Creating a likeness and index of the phenomenal world. Visual Communication, 5, nr. 3, 345-366.

Matsumoto, D. (2002). The new Japan. Debunking seven cultural stereotypes. Yarmouth: Intercultural Press Inc.

McQuail, D. (2000). McQuail's mass communication theory. Londen: Sage.

Minear, R.H. (I980). Orientalism and the study of Japan. Journal of Asian Studies, 39, nr. 3, 507-517.

Mitsuhiro, Y. (I989). The postmodern and mass images in Japan. Public Culture, 1, nr. 2, 8-25.

Nishihara, D. (2005). Said, Orientalism, and Japan. Alif: Journal of Comparative Poetics, 25, $24 \mathrm{I}-253$.

Pantti, M. (2009). Wave of compassion. Nationalist sentiments and cosmopolitan sensibilities in the Finnish press coverage of the tsunami disaster. In U. Kivikuru \& L. Nord (Eds.), After the tsunami. Crisis communication in Finland and Sweden (pp. 83-106). Göteborg: Nordicom.

Phillips, L. (2006). Doing Discourse Analysis. A brief introduction to the field. In N. Carpentier et al. (Eds.), Media technologies and democracy in an enlarged Europe (pp. 285-294). Tartu: Tartu University Press.

Rosen, S.L. (2000). Japan as Other: Orientalism and cultural conflict. Intercultural Communication, 4. http://www.immi.se/jicc/index.php/jicc/article/view/ı45/ıı2

Said, E. (2003). Orientalism. Western conceptions of the Orient (reprint). Londen: Penguin Books.

Shadid, W. (2005). Berichtgeving over moslims en de islam in de westerse media: Beeldvorming, oorzaken en alternatieve strategieën. Tijdschrift voor Communicatiewetenschap, 39, nr. 4, 330-346.

Shohat, E. \& Stam, R. (I994). Unthinking Eurocentrism: Multiculturalism and the media. Londen: Routledge.

Silverstone, R. (2007). Media and morality: On the rise of the Mediapolis. Cambridge: Polity Press.

Smith, P. \& Bell, A. (2007). Unravelling the web of Discourse Analysis. In E. Devereux (Ed.), Understanding the Media (pp. 78--100). Londen: Sage.

Steadman, J.M. (I970). The Myth of Asia. Londen: Macmillan.

Ueno, T. (2002). Japanimation: Techno-Orientalism, media tribes and rave culture. In Z. Sardar \& S. Cubitt (Eds.), Aliens R Us. The Other in science fiction cinema (pp. 94-IIo). Londen: Pluto Press.

Van Dijk, T.A. (I988). News analysis: case studies of international and national news in the press. Hillsdale (N.J.): Erlbaum.

Van Dijk, T.A. (2009). News, discourse, and ideology. In K. Wahl-Jorgensen \& T. Hanitzsch (Eds.), The handbook of journalism studies (pp. I9I-204). New York: Routledge.

Van Hintum, M. (20II, 26 maart). Japanners huilen ook. De Volkskrant, p. 6.

Van den Bulck, H. \& Broos, D. (2009). When 'us' meet 'them': The representation and reception of Muslim women in a Flemish documentary. In E. Castelló, A. Dhoest \& H. O’Donnell (Eds.), The nation on screen: discourses of the national on global television (pp. I57-I76). Cambridge: Cambridge Scholars Publishing.

Wester, F. \& Peters, V. (2004). Kwalitatieve analyse. Uitgangspunten en procedures. Bussum: Uitgeverij Coutinho.

Westerik, H., Douma, L. \& Konig, R. (2007). Tv-kijken, stereotypering, attitudevorming en discriminatie van Duitsers. Tijdschrift voor Communicatiewetenschap, 35, nr. 1, 37-58. 
230 | Tijdschrift voor Communicatiewetenschap - 40 [3] 2012

\section{Noten}

I In Nederland werd Lost in Tokyo na amper vier van de tien geplande afleveringen stopgezet wegens de tegenvallende kijkcijfers.

2 De laatste aflevering was de ontknoping/een compilatie van het seizoen en speelde zich af in Nederland. 